\title{
Quantifying the sampling error in tree census measurements by volunteers and its effect on carbon stock estimates
}

\author{
Nathalie Butt,,${ }^{1,2,5}$ Eleanor Slade,${ }^{3}$ Jill Thompson,,${ }^{4}$ Yadvinder Malmi, ${ }^{1}$ and Terhi Riutta ${ }^{1}$ \\ ${ }^{1}$ Oxford University School of Geography and the Environment, Dyson Perrins Building, South Parks Road, \\ Oxford OX1 3QY United Kingdom \\ ${ }^{2}$ School of Biological Sciences, University of Queensland, St. Lucia 4072, Brisbane, Australia \\ ${ }^{3}$ Wildlife Conservation Research Unit, Department of Zoology, University of Oxford, The Recanati-Kaplan Centre, \\ Tubney House, Abingdon Road, Tubney, Abingdon OX13 5QL United Kingdom \\ ${ }^{4}$ Centre for Ecology and Hydrology, Bush Estate, Penicuik, Midlothian EH26 OQB United Kingdom
}

\begin{abstract}
A typical way to quantify aboveground carbon in forests is to measure tree diameters and use species-specific allometric equations to estimate biomass and carbon stocks. Using "citizen scientists" to collect data that are usually time-consuming and labor-intensive can play a valuable role in ecological research. However, data validation, such as establishing the sampling error in volunteer measurements, is a crucial, but little studied, part of utilizing citizen science data. The aims of this study were to (1) evaluate the quality of tree diameter and height measurements carried out by volunteers compared to expert scientists and (2) estimate how sensitive carbon stock estimates are to these measurement sampling errors. Using all diameter data measured with a diameter tape, the volunteer mean sampling error (difference between repeated measurements of the same stem) was $9.9 \mathrm{~mm}$, and the expert sampling error was $1.8 \mathrm{~mm}$. Excluding those sampling errors $>1 \mathrm{~cm}$, the mean sampling errors were $2.3 \mathrm{~mm}$ (volunteers) and $1.4 \mathrm{~mm}$ (experts) (this excluded $14 \%$ [volunteer] and $3 \%$ [expert] of the data). The sampling error in diameter measurements had a small effect on the biomass estimates of the plots: a volunteer (expert) diameter sampling error of $2.3 \mathrm{~mm}(1.4 \mathrm{~mm})$ translated into $1.7 \%(0.9 \%)$ change in the biomass estimates calculated from species-specific allometric equations based upon diameter. Height sampling error had a dependent relationship with tree height. Including height measurements in biomass calculations compounded the sampling error markedly; the impact of volunteer sampling error on biomass estimates was $\pm 15 \%$, and the expert range was $\pm 9 \%$. Using dendrometer bands, used to measure growth rates, we calculated that the volunteer (vs. expert) sampling error was $0.6 \mathrm{~mm}$ (vs. $0.3 \mathrm{~mm}$ ), which is equivalent to a difference in carbon storage of $\pm 0.011 \mathrm{~kg} \mathrm{C} / \mathrm{yr}$ (vs. $\pm 0.002 \mathrm{~kg} \mathrm{C} / \mathrm{yr}$ ) per stem. Using a citizen science model for monitoring carbon stocks not only has benefits in educating and engaging the public in science, but as demonstrated here, can also provide accurate estimates of biomass or forest carbon stocks.
\end{abstract}

Key words: biomass estimate; carbon stocks; citizen science; data quality; forest monitoring; tree measurements; Wytham Woods, Oxfordshire, United Kingdom.

\section{INTRODUCTION}

With increased pressure on our natural resources, and growing public awareness of, and interest in, sustainable environmental management, there is an increasing need to collect data of sufficient quantity and quality to inform effective management decisions. Using volunteer data collectors, or "citizen scientists" (sensu Irwin 2001), enhances the scope and range of scientific data collection by supplementing scarce data collection resources and enabling data to be collected on larger scales (Devictor et al. 2010, Dickinson et al. 2010). This is not a new development; for example, the United Kingdom-based Royal Society for the Protection of Bird's "Big Garden

Manuscript received 17 November 2011; revised 10 October 2012; accepted 21 November 2012. Corresponding Editor: S. Henderson.

${ }^{5}$ E-mail: n.butt@uq.edu.au
Watch" has been running for over 30 years and in 2011 more than 600000 people took part (RSPB 2011; see also Dickinson et al. 2010), but recent years have seen an increase in the variety of studies that utilize citizen scientists. The societal benefits of nonprofessional engagement in such environmental research are welldocumented, and range from raising awareness of environmental issues at both project-specific and wider levels to realizing or intensifying personal relationships with nature and communicating knowledge and experience to others (Newman et al. 2003, Lovell et al. 2009).

Several surveys in the United Kingdom, United States, and Australia have used volunteer-collected data for moths, plants, amphibians, marine species, and birds (Greenwood 2007, Lotz and Allen 2007, Delaney et al. 2008, Milberg et al. 2008, Fox et al. 2010, Szabo et al. 2010); in 2008 the Ecological Society of America included a symposium to discuss the philosophy, 
validity, and value of citizen science at that year's annual meeting (Cohn 2008), and in 2012 Frontiers in Ecology and the Environment dedicated a Special Issue to an exposition of new techniques and lessons learned from a range of different projects around the world (Henderson 2012). The number of reports and papers analyzing the contribution of volunteer participation to scientific fieldwork is growing (e.g., Eden 1996, Schmeller et al. 2008), and several studies have elucidated the problems as well as the advantages of this type of data collection (Trumbull et al. 2000, Newman et al. 2003, Dickinson et al. 2010, Cox et al. 2012).

In situations where large amounts of data need to be collected over large areas to provide both baseline data (for example, for national forest inventories) and repeated survey data (re-census data to estimate change), and governments or agencies do not have large financial resources for this, citizen science can play a valuable role in the type of ecological research that is usually costly, time-consuming, and labor-intensive (Newman et al. 2003, Lovell et al. 2009). However, there are concerns over the reliability of data collected by unskilled volunteers (Darwall and Dulvy 1996, Foster-Smith and Evans 2003).

Currently there is great interest in forests as carbon stocks, and where carbon storage equals money (e.g., the UN Programme for Reducing Emissions from Deforestation and Forest Degradation, REDD+; information available online), ${ }^{6}$ it is vital for measurements, and thus carbon stock estimates, to be as accurate as possible. Data validation, establishing the range of uncertainty or bias in volunteer measurements, is therefore a crucial part of utilizing citizen science data. Recently, for instance, Fitzpatrick et al. (2009) reported that volunteers failed to identify small infestation occurrences of an insect pest in hemlock forests, while Milberg et al. (2008) found that during a vegetation surveying exercise up to $30 \%$ of presence frequency data were missed by nonexperts, but that the bias in percent cover estimate was relatively low. Techniques such as active collecting and capture of moving invertebrates and specimen recognition and identification are methods that present particular difficulties for nonspecialist volunteers, but studies suggest that if the survey techniques are kept simple, and the subjectivity of the methods minimized, volunteers could be almost as good as experienced experts (Lovell et al. 2009). Measurement of tree diameters, a relatively nonsubjective method on a stationary object, should present fewer problems for inexperienced volunteers. The effect of variation in tree diameter measurements on biomass calculations has been partially assessed in relation to the height of diameter measurements (Brokaw and Thompson 2000), the impact on modeled biomass estimates (Gertner 1990, Melson et al. 2011), and measurement error as

\footnotetext{
${ }^{6}$ www.un-redd.org/
}

quantified by the USDA Forest Service (Phillips et al. 2000), but analyses of direct comparison of repeated measurements are lacking. To increase volunteer efficiency and understanding of the tasks, the activities should be contextualized (Lovell et al. 2009), such as by explaining the link between tree measurements and the amount of carbon in a forest, and the way these data can be used. As this is easy to demonstrate for trees and forests using relatively straightforward methods, this type of research provides an ideal study for the involvement of citizen scientists.

A four-year forest monitoring program based in Wytham Woods, Oxfordshire, United Kingdom, has generated a large amount of measurement data collected by volunteers funded by HSBC bank through an Earthwatch program (information available online) ${ }^{7}$ and provided the perfect opportunity to (1) compare volunteer and expert sampling error in tree measurement data in order to assess the quality of volunteer data, and (2) apply these sampling errors to tree biomass and carbon storage estimates, and to calculate range of uncertainty values in order to establish how sensitive these estimates are to measurement sampling errors.

\section{Methods \\ Site description}

Wytham Woods $\left(1^{\circ} 20^{\prime} \mathrm{W}, 51^{\circ} 47^{\prime} \mathrm{N}\right)$ lies $\sim 5 \mathrm{~km}$ northwest of Oxford, in southern England. The site was given to Oxford University in 1943 and since then has become one of the most researched woodlands in Europe; birds, mammals, and invertebrates have been intensively studied here (Savill et al. 2010). In 2008, through the financial support of HSBC bank, this site became the European Regional Climate Centre of the Earthwatch Institute's global network of forest plots (see Shetty 2011; information available online). ${ }^{8}$

The tree and ground flora of Wytham have been extensively studied over many decades (e.g., Kirby et al. 1996), and data from the Earthwatch monitoring plots are providing key information on changes in forest dynamics, productivity, and carbon stocks that will be used to investigate the potential impact of changing climatic conditions in the future. The wood falls into the category of W8 Fraxinus excelsior-Acer campestreMercurialis perennis woodland, following the National Vegetation Classification (NVC; Rodwell 1991). This type of woodland community is diverse and variable in both the ground flora and tree species composition and structure (see Butt et al. 2009 for further information). There are 10 Earthwatch monitoring plots, $\sim 1$ ha in size, around Wytham Hill and nearby woods, which represent forest "edge," "fragment," and "core" woodland habitat. One of the Earthwatch 1-ha plots lies within a larger long-term forest monitoring plot (Butt et

\footnotetext{
${ }^{7}$ http://www.earthwatch.org/europe/hcp

8 http://www.earthwatch.org/europe/rcc_europe
} 
al. 2009), which is part of the Smithsonian Institution Global Earth Observatory project (available online). ${ }^{9}$

\section{Earthwatch Climate Champion program}

The objectives of the Earthwatch program were to quantify how the woodland carbon cycle and productivity varies between forest core areas and edges and between large and small fragments, under current and changing climatic conditions. Over four years, 260 volunteers collected aboveground carbon-stock measurement data: tree diameters, tree heights, and stem growth data using dendrometer bands. The volunteers were HSBC bank employees, from U.K. and international branches, engaged in the Climate Champion Programme who spent one or two weeks at the Regional Climate Centre learning about climate change and environmental science and working with scientists to collect forest monitoring data (see footnote 8). The data both provided a baseline for long-term monitoring of changes in carbon stocks and enabled comparisons among tree species, sites, seasons, and years. Teams of 12 volunteers were trained by Earthwatch staff, and each team spent between two and seven days making field measurements of tree diameters, heights, or dendrometer bands. After an hour of classroom and in-field instruction and training, the volunteers worked in groups of three, under the supervision of two or three Earthwatch field staff. Close supervision was not generally required once the volunteers had started taking measurements but field staff members were available for advice and support if required. Data entry into a computer was carried out later, in pairs.

\section{Data collection}

All the plots in the Earthwatch network have a common plot structure and scientific methodology, following that applied in the Smithsonian plot (Condit 1998). At each site, a 1-ha plot was marked out and 25 $20 \times 20 \mathrm{~m}$ subplots were delimited within it. Each stem with a diameter at breast height (dbh, usually $1.3 \mathrm{~m}$ ) (Condit 1998, Brokaw and Thompson 2000), of $\geq 5 \mathrm{~cm}$ was included in the tree census. Each stem was tagged with a unique tag number, identified to species (by the volunteers guided by the experts), marked with paint or ink at the point of measurement, and located on a map using the east-west and north-south boundaries of the subplot as axes. Diameters were measured to the nearest $0.05 \mathrm{~cm}$ using a diameter tape, tree height measurements were made in meters using a clinometer, and dendrometers were measured in millimeters to the nearest 0.01 $\mathrm{mm}$ using digital calipers. The diameter measurements were used to calculate the standing stocks, the height measurements were combined with the diameter measurements to calculate volume, and the dendrometer measurements enabled us to calculate tree growth and

${ }^{9}$ http://www.ctfs.si.edu/site/Wytham+Woods carbon accumulation at regular intervals. The trees that were remeasured by the Earthwatch volunteers were a randomly selected subsample from several of the plots and different volunteer groups at different times of year, depending upon where the field teams were working. For each of these trees two measurements were made, during the same fieldwork week, by different fieldworkers.

The "expert" measurements were made in the same way as the volunteers, with six different staff members taking repeat measurements in two of the plots. Experts were Earthwatch field staff and Oxford University scientists who had hundreds of hours of measurement experience over a period of two to four years. For the diameter analysis, measurements for 800 trees were made by volunteers, and 100 trees by the experts; for the height analysis 250 volunteer measurements and 100 expert measurements were made, and dendrometer measurements were taken for 100 trees by both volunteers and experts. To test whether the larger volunteer sample sizes had an effect on the results, subsamples of 100 diameter and height measurements from the volunteer data set (the same number of trees measured by the expert group) were also tested.

\section{Data analysis}

Here we assess the difference between repeated measurements of the same tree taken by different people. As we do not know the "correct" measurement for each tree, because we have no information other than two measurements for each stem, we cannot calculate the absolute error in the measurements. Instead we calculate the "sampling error," or variation in observations, as defined by Dickinson et al. (2010). Diameter measurements were divided into two categories: clear mistakes (where the error was most likely a result of transcription or data entry in the field rather than an actual measurement error; errors $>1 \mathrm{~cm}$ ), and sampling error (variation in the spread of observations). The differences between volunteer and expert measurements were investigated using $t$ tests and Pearson's correlation analyses.

To assess the effect of the measurement uncertainty on forest carbon stocks, the aboveground (standing) biomass was calculated per hectare for trees in the 18-ha Smithsonian plot using species-specific formulae for Acer pseudoplatanus (L.), Fraxinus excelsior (L.), and Quercus robur (L.) (see Bunce 1968) derived from a similar woodland; and for the remaining species a mean calculated from these three species' equation constant (b) and coefficients (a) was used (Eq. 1), and C\% = dry mass $\times$ species-specific carbon content $(A$. pseudoplatanus, $a=-5.64407, b=2.518916 ; F$. excelsior, $a=$ $-5.30813, b=2.488218 ; Q$. robur, $a=-5.2486, b=$ 2.468257; other species, $a=-5.34768, b=2.47536$ ). The conversion from biomass (dry mass) to $\mathrm{Mg} \mathrm{C}$ values used species-specific fractional carbon contents of 0.469 $\pm 0.008 \mathrm{~g} \mathrm{C} / \mathrm{g}(\mathrm{mean} \pm \mathrm{SE})$ for A. pseudoplatanus, 0.491 
$\pm 0.05 \mathrm{~g} \mathrm{C} / \mathrm{g}$ for F. excelsior, and $0.474 \pm 0.005 \mathrm{~g} \mathrm{C} / \mathrm{g}$ for $Q$. robur. The mean value of $0.477 \pm 0.003 \mathrm{~g} \mathrm{C} / \mathrm{g}$ was used for all other species (cf. Fenn et al. 2010), as follows:

$$
\text { Dry mass (biomass) }=\exp (\ln (\pi d) a+b)
$$

We applied the diameter and height sampling error values to these calculations using the large Smithsonian plot data set to give a plus-or-minus carbon and biomass estimate per hectare, and refer to the range of this estimate as the range of uncertainty, whereby we mean that uncertainty is a function of the lack of a known correct diameter measurement. To quantify the effect of the uncertainty in height on biomass estimates, we used species-specific stem volume equations (Eq. 2) that include both height and diameter, from the compilation by Zianis et al. (2005), and converted the volume into biomass using species-specific wood density values from the global wood density database (available online). ${ }^{10}$ The volume equation coefficients and wood density values for the three main tree species are as follows: $A$. pseudoplatanus, $a=-0.012668, b=7.37 \times 10^{-5}, c=0.75$ (Eq. 2), wood density, $620 \mathrm{~kg} / \mathrm{m}^{3} ; F$. excelsior, $a=$ $-0.01211, b=7.77 \times 10^{-5}, c=0.75$, wood density, 640 $\mathrm{kg} / \mathrm{m}^{3} ; Q$. robur, $a=-0.01172, b=7.65 \times 10^{-5}, c=0.75$, wood density, $705 \mathrm{~kg} / \mathrm{m}^{3}$. We calculated the biomass estimates assuming that there was an error only in the diameter measurements, only in the height measurements, and in both, as follows:

$$
\text { Volume }\left(\mathrm{dm}^{3} ; \text { biomass proxy }\right)=a+b \mathrm{D}^{2} \mathrm{H}^{c} .
$$

The dendrometer data sampling error was applied to monthly dendrometer data to give an annual range of uncertainty in kilograms of carbon per stem.

\section{RESUlts}

Differences in sampling errors between the volunteer and expert groups were marked, and height measurements showed the most variation, but the volunteercollected data were generally good quality. Volunteer mean sampling error in measuring tree diameters was 9.9 $\mathrm{mm}$ and the expert mean sampling error was $1.8 \mathrm{~mm}$. Excluding errors $>1 \mathrm{~cm}$, the values were 2.3 and 1.4 $\mathrm{mm}$, respectively (excluding 14\% [for volunteers] and 3\% [for experts] of the data). The difference between the volunteer and expert measurement sampling error was significant for comparisons both using all 800 volunteer samples $\left(t_{860}=-4.82, P<0.001\right.$ for all data; $t_{301}=$ $-7.79, P<0.001$, excluding differences $>1 \mathrm{~cm})$ and for a subsample of 100 volunteer measurements $\left(t_{100}=-2.52\right.$, $P=0.01)$. The mean sampling error for the 100 sample subset of volunteer measurements was $0.49 \mathrm{~mm}$. The median diameter sampling error was $0.2 \mathrm{~cm}$ for

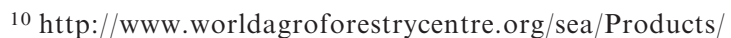
AFDbases/WD/
}

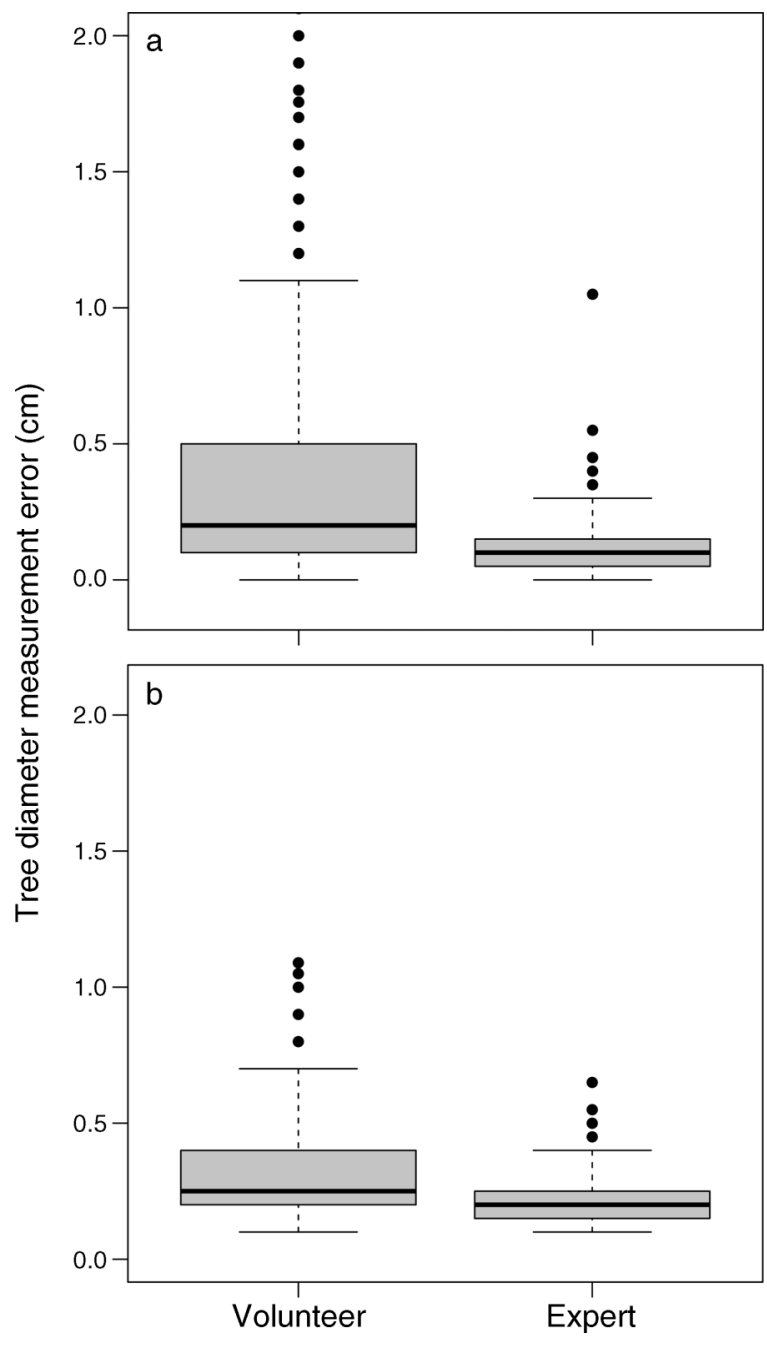

FIG. 1. Median, first and third quantiles, and range of diameter measurement sampling error, volunteer and expert, for (a) all data and (b) excluding errors $>1 \mathrm{~cm}$. Outliers fall outside $85 \%$ of data, marked by the whiskers. Sampling errors for the volunteer data in panel (a) that exceed $2 \mathrm{~cm}$ are not shown in this figure (61 measurements).

volunteers and $0.1 \mathrm{~cm}$ for experts and the variation around these was also larger for volunteers (Fig. 1).

Breaking down the sampling errors into diameter size classes showed that the largest trees $(>45 \mathrm{~cm} \mathrm{dbh})$ were a significantly greater source of volunteer error than smaller trees $\left(t_{54}=-3.11, P<0.01\right.$ for trees $<45 \mathrm{~cm} \mathrm{dbh}$ compared with trees $>45 \mathrm{~cm} \mathrm{dbh}$ ), while there was no trend by size for the expert error data (Fig. 2). There was no diameter sampling error trend by species for either group ( $P>0.05$ in both cases).

Excluding the "clear errors" and using only the data with errors $<1 \mathrm{~cm}$, the sampling error in diameter had a small effect on the biomass estimates of the plots of approximately $\pm 1.7 \%$ for the volunteer data and $<1 \%$ for the experts. Using all of the data, the biomass estimate range, the range of uncertainty, was approxi- 


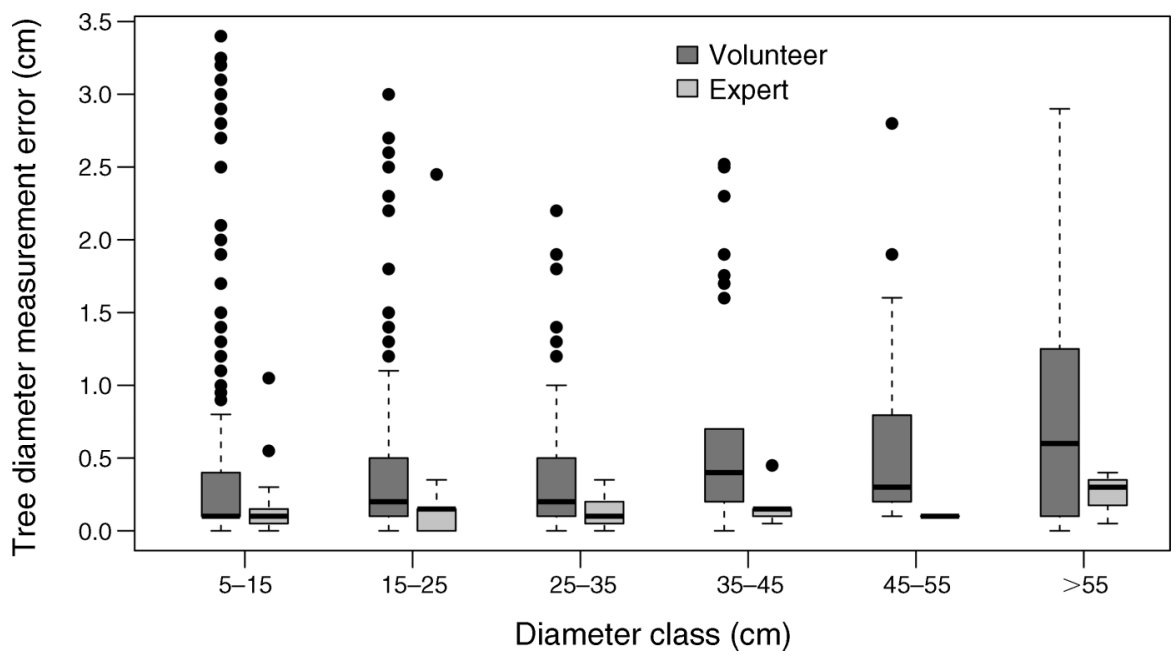

FIG. 2. Median, first and third quantiles, and range of sampling error by tree size class for each group. There are so many outliers in the $5-15 \mathrm{~cm}$ class because $50 \%$ of the total measurements are in this size class.

mately $\pm 7 \%$ for the volunteers and $\sim 1 \%$ for the experts (Fig. 3). Height sampling error had a dependent relationship with tree height: the taller the tree, the greater the error. Pearson correlation coefficients were 0.67 and 0.52 for volunteer and expert data, respectively $(P<0.01$ for both groups). The slope was markedly lower for expert than volunteer measurements $(0.11$ and 0.19, respectively; Fig. 4). Overall, the mean volunteer sampling error was $2.8 \mathrm{~m}$ and the maximum error was 20 $\mathrm{m}$, while for experts the mean height sampling error was $1.6 \mathrm{~m}$ and the maximum was $7 \mathrm{~m}$. The differences between the volunteer and expert measurement sampling errors was significant when using all data $\left(t_{288}=4.71, P\right.$ $<0.0001)$ and also when using a subsample of 100 volunteer data measurements $\left(t_{154}=-3.72, P<0.001\right)$.

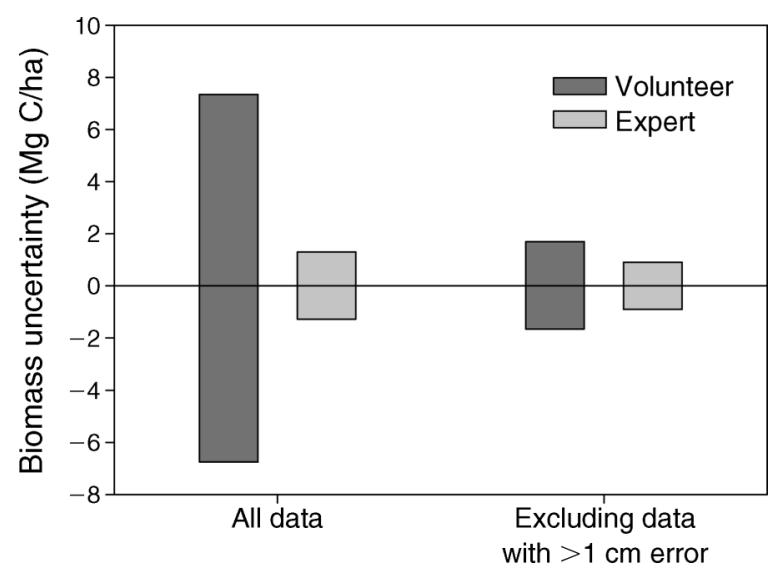

FIG. 3. Impact of diameter measurement sampling error on carbon biomass estimate ( $\mathrm{Mg} \mathrm{C} / \mathrm{ha})$. Columns above and below the line represent the plus-or-minus range of uncertainty, as calculated from the measurements for the two data sets, by observer group.

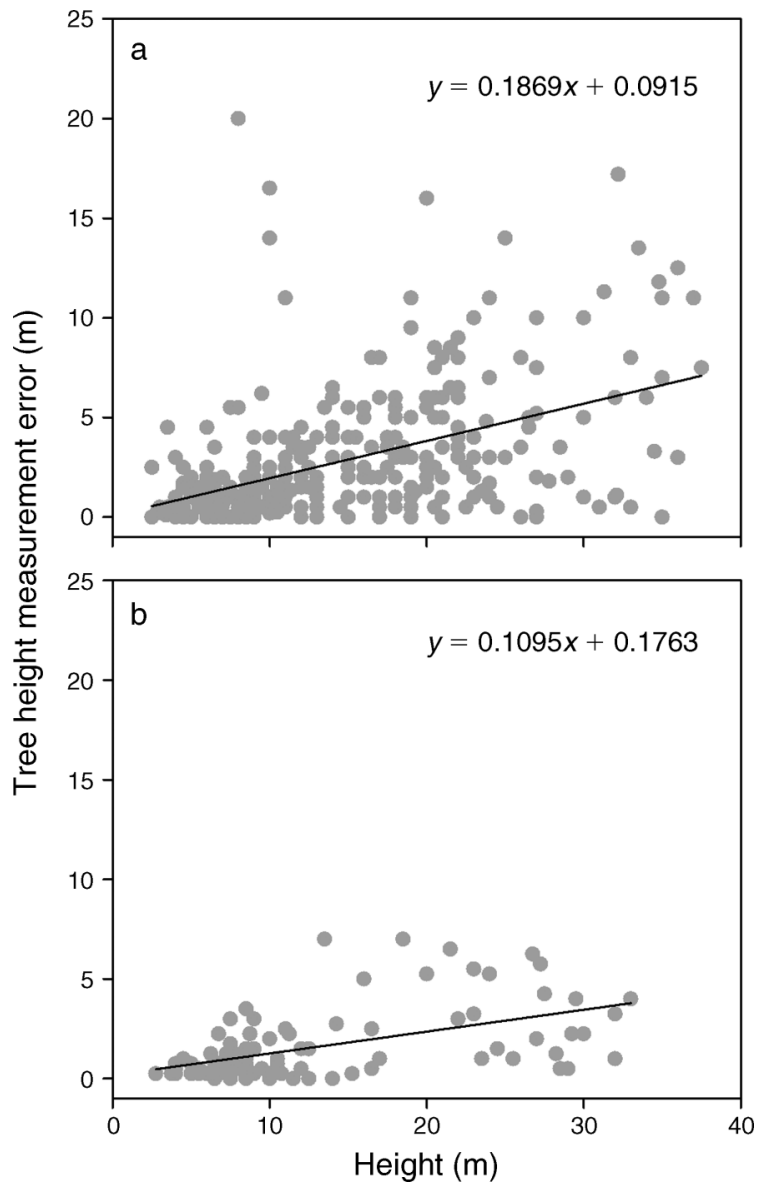

FIG. 4. Height measurement sampling error for (a) volunteers (800 measurements) and (b) experts (100 measurements). Slope values are included for each group. 


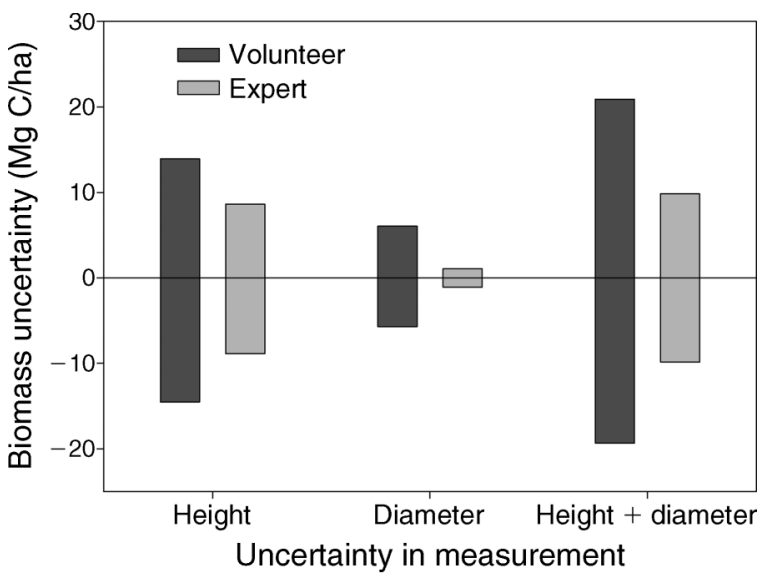

FIG. 5. Impact of measurement sampling error on carbon stock estimates derived from volume equations and wood density assuming uncertainty in height measurements only, uncertainty in diameter measurements only, and uncertainty in both height and diameter measurements combined. Columns above and below the line represent the plus-or-minus range of uncertainty, as calculated from the measurements for the two data sets, by observer group.

The mean sampling error for the 100 sample subset of volunteer measurements was $2.9 \mathrm{~m}$.

Including height measurements in biomass calculations markedly compounded the error (Fig. 5); the volunteer range of uncertainty impact on biomass proxy estimates (as a volume) was $\pm 15 \%\left(\mathrm{~m}^{3} / \mathrm{stem}\right)$ and the expert range was $\pm 9 \%\left(\mathrm{~m}^{3} / \mathrm{stem}\right)$.

Dendrometer measurement sampling error was significantly greater for volunteers at $0.6 \mathrm{~mm}$, compared with $0.3 \mathrm{~mm}$ for experts $\left(t_{110}=2.17, P<0.05\right)$. The median value for volunteer data was 0.3 and for expert 0.26 , and the range in the volunteer data was greater than that of the experts (Fig. 6). The percentage error in measurements derived from dendrometer data was smaller than that derived from diameter measurements.

Application of these sampling errors to annual growth increment estimates of $\sim 10 \mathrm{~mm} / \mathrm{stem}$, calculated from all monthly dendrometer data for March 2010-February 2011, gives an annual range of uncertainty of $\pm 6 \%$ and $3 \%$ for volunteer and expert, respectively. This translates into a carbon biomass estimate impact of $\pm 0.011 \mathrm{~kg} \mathrm{C} / \mathrm{stem}$ annual growth for volunteers and $\pm 0.002 \mathrm{~kg} \mathrm{C} /$ stem annual growth for experts, based on allometric equations.

Overall, the sampling error for height measurements had the greatest impact on the range of uncertainty of biomass estimation, for both volunteers and experts. The impact of diameter and dendrometer measurement sampling error was similar between these two measurements within each group, but the expert measurement sampling error had a significantly smaller impact on biomass estimation than volunteer sampling error in both cases.
DISCUSSION

This study highlights the potential impact of the difference in quality between volunteer and expert measurements when using citizen scientists to collect data that will be used to estimate carbon stocks of forests. Diameter measurements had a sampling error of $9.9 \mathrm{~mm}$ for volunteers and $1.8 \mathrm{~mm}$ for experts. The volunteer range of uncertainty for biomass calculated using diameter measurement data only was $\pm 7 \%$ for all data; the equivalent expert value was $\pm 1 \%$. Including height data in allometric calculations compounded the range of uncertainty in biomass estimates by $\pm 30 \%$.

In general, the tree census carried out by volunteers provides good quality data. The sampling errors, as translated into ranges of uncertainty, did not make a biologically significant difference to estimates of biomass or carbon stocks. The situation can therefore be thought of in terms of a trade-off between obtaining large amounts of data over a large area and potentially more frequently, or having data always collected by "experts" who are more accurate but also expensive and able to complete field measurements less frequently and over a smaller area. In a census such as this study, data validation can only be achieved (1) by duplicating the data collection effort so that the differences between measurements can be directly measured, or (2) by using earlier census data. Comparing census data taken in different years does not provide the same level of analysis of accuracy, as sampling error in the second census is reduced by already having data from the first census. This is especially true if the second census measurement appears smaller than the first when tree growth would be more likely than stem shrinkage. Although the sampling error and range of uncertainty for dendrometer measurements was smaller than for

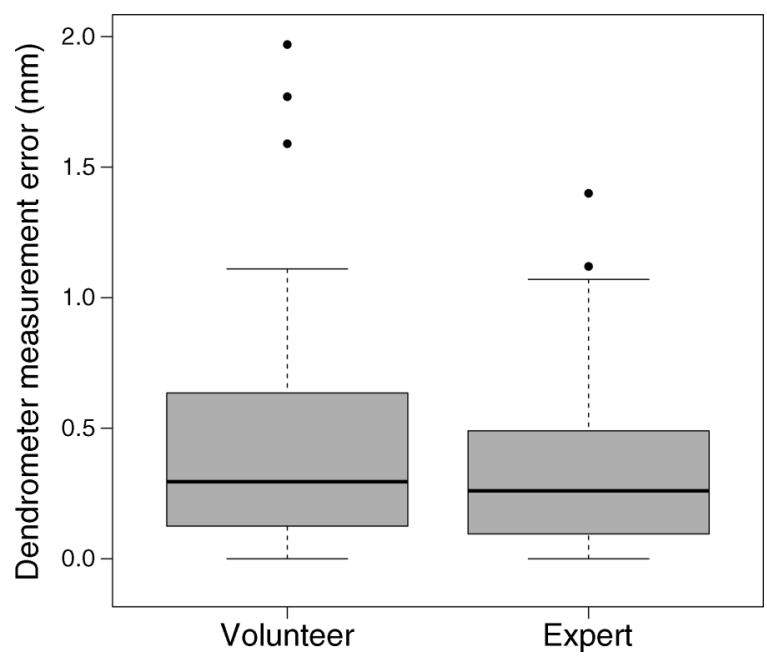

FIG. 6. Median, first and third quantiles, and range of dendrometer measurement sampling error for volunteers and experts. Sampling errors for the volunteer data that exceed 2 $\mathrm{mm}$ (three measurements) are not shown in this figure. 
diameter measurements, dendrometers are more expensive and time-consuming to apply, require adjustment over long periods, and it would not be practical to fit them to every single tree measured; they are useful for growth increment monitoring rather than large-scale census.

While different types of data collection projects may provide opportunities for data validation by seeking further information, at a later date, from the volunteers who collected the data (Dickinson et al. 2010), where measurements are only made once there is no way to identify errors, and data validation is impossible. In these cases, using the larger of the range of uncertainties, as reported (see Results), is perhaps more widely applicable to other studies using volunteer data collection, as clear errors cannot be excluded from data analyses where there is only one measurement taken.

In terms of observer quality, which refers to the variation in the ability of different data collectors or groups of data collectors (Dickinson et al. 2010), expert measurements are of better quality than volunteer measurements. However, the results show that volunteers can collect useful data. The volunteers in this study received training both before the fieldwork and further training and supervision during it, and they all spent at least two days collecting data, underlying the importance of effective training and in-field supervision (Lovell et al. 2009). Volunteers are generally not as efficient as an expert in terms of time (Newman et al. 2003, Dickinson et al. 2010) (in this study they worked in groups of three supervised by one expert); however, teams of volunteers may compensate for lack of experience and speed by increasing effort through increased numbers of people collecting data.

Lovell et al. (2009) demonstrate that volunteers can provide useful data under specific conditions related to training and supervision, simplicity of methods, volunteer/supervisor numbers, and that the benefits of using volunteer data collection include the volume of fieldwork that can be accomplished and the large areas that can be covered (Devictor et al. 2010). With these caveats, they conclude that volunteer data collection should only be used where meaningful contributions are made and the work would otherwise not be done. This study provides an example of this type of research; the volunteers collected tree diameter and height and growth data from 10 plots on a regular basis over four years, enabling re-censusing of all the plots and monthly growth monitoring. The collection of this quantity of data at such a high temporal resolution would have been difficult to achieve without their contribution.

In addition to the scientific benefits of this work there are direct and indirect social benefits to the volunteers participating in research programs, and therefore to society in general. These benefits include: increasing environmental awareness and understanding of environmental issues; developing an active interest in woodlands and nature; improvement in their perception of "nature"; increasing their sense of connectedness to and responsibility for the environment; and ability to share their experience and knowledge with other nonscientists (Newman et al. 2003, Lovell et al. 2009).

\section{CONCLUSION}

This study shows that forest-monitoring research is an ideal area for the involvement of citizen scientists. Where large amounts of nonsubjective, easy-to-collect data need to be collected over large spatial and temporal scales, we show that volunteers can collect good quality data, which has little impact overall on carbon biomass estimates. Although the data collected by volunteers are of a slightly lower quality than that of experts, we believe that it is within an acceptable range, and the volumes of data that can be collected using teams of volunteers more than compensates for these small inaccuracies. With the interest in mapping the world's forests for carbon through schemes such as REDD+, but a lack of funding and experts to achieve this, we suggest that using the large base of citizen scientists may be one way to not only fill this critical data gap but also to provide opportunities for the education and engagement of the public in science, and its use in policy, and thus to address the wider goals of citizen science.

\section{ACKNOWLEDGMENTS}

We thank the Earthwatch/HSBC volunteer teams, and the "expert" Earthwatch staff: Kate Barker, Paul Eddowes, Richard Sylvester, and Ellie Gilvin. We are also grateful to Gordon Campbell, Chloe Wells, Rowena Millard, Dan Bebber, and Mike Morecroft, and the Smithsonian plot fieldworkers. We thank Phil Smith and Nigel Fisher for their support and permission to work at the study site. Thanks also to the two anonymous referees for their helpful input. The study was funded by the HSBC Climate Partnership Programme through the Earthwatch Institute.

\section{Literature Cited}

Brokaw, N., and J. Thompson. 2000. The h for dbh. Forest Ecology and Management 129:89-91.

Bunce, R. G. H. 1968. Biomass and production of trees in a mixed deciduous woodland: I. Girth and height as parameters for the estimation of tree dry weight. Journal of Ecology 56:759-775.

Butt, N., G. Campbell, Y. Malhi, M. Morecroft, K. Fenn, and M. Thomas. 2009. Initial results from establishment of a long-term broadleaf monitoring plot at Wytham Woods, Oxford, UK. University of Oxford Report. http://www.eci. ox.ac.uk/publications/downloads/butt09-wythamwoods.pdf

Cohn, J. P. 2008. Citizen science: Can volunteers do real research? BioScience 58:192-197.

Condit, R. 1998. Tropical forest census plots: methods and results from Barro Colorado Island, Panama and a comparison with other plots. Springer-Verlag, Heidelberg, Germany.

Cox, T. E., J. Philippoff, E. Baumgartner, and C. M. Smith. 2012. Expert variability provides perspective on the strengths and weaknesses of citizen-driven intertidal monitoring program. Ecological Applications 22:1201-1212.

Darwall, W., and N. Dulvy. 1996. An evaluation of the suitability of non-specialist volunteer researchers for coral reef fish surveys. Mafia Island, Tanzania - a case study. Biological Conservation 78:223-231. 
Delaney, D. G., C. D. Sperling, C. S. Adams, and B. Leung. 2008. Marine invasive species: validation of citizen science and implications for national monitoring networks. Biological Invasions 10:117-128.

Devictor, V., R. Whittaker, and C. Beltrame. 2010. Beyond scarcity: citizen science programmes as useful tools for conservation biogeography. Diversity and Distributions 16:354-362.

Dickinson, J. L., B. Zuckerberg, and D. N. Bonter. 2010. Citizen science as an ecological research tool: challenges and benefits. Annual Review of Ecology, Evolution, and Systematics 41:149-172.

Eden, S. 1996. Public participation in environmental policy: considering scientific, counter-scientific and non-scientific contributions. Public Understanding of Science 5:184-204.

Fenn, K., Y. Malhi, M. Morecroft, C. Lloyd, and M. Thomas. 2010. Comprehensive description of the carbon cycle of an ancient temperate broadleaved woodland. Biogeosciences Discussions 7:3735-3763.

Fitzpatrick, M. C., E. L. Preisser, A. M. Ellison, and J. S. Elkington. 2009. Observer bias and the detection of lowdensity populations. Ecological Applications 19:1973-1679.

Foster-Smith, J., and S. Evans. 2003. The value of marine ecological data collected by volunteers. Biological Conservation 113:199-213.

Fox, R., Z. Randle, S. Anders, L. Wiffen, and M. Parsons. 2010. Moths count: recording moths for conservation in the UK. Journal of Insect Conservation 15:55-68.

Gertner, G. Z. 1990. The sensitivity of measurement error in stand volume estimation. Canadian Journal of Forest Research 20:800-804.

Greenwood, J. J. D. 2007. Citizens, science and bird conservation. Journal of Ornithology 148 (Supplement 1):S77-S124.

Henderson, S. 2012. Citizen science comes of age. Frontiers in Ecology and the Environment 10:283.

Irwin, A. 2001. Constructing the scientific citizen: science and democracy in the biosciences. Public Understanding of Science 10:1-18.

Kirby, K. J., R. C. Thomas, and H. C. Dawkins. 1996. Monitoring of changes in tree and shrub layers in Wytham Woods (Oxfordshire), 1974-1991. Forestry 69:319-334.

Lotz, A., and C. R. Allen. 2007. Observer bias in anuran call surveys. Journal of Wildlife Management 71:675-679.
Lovell, S., M. Hamer, R. Slotow, and D. Herbert. 2009. An assessment of the use of volunteers for terrestrial invertebrate biodiversity surveys. Biodiversity and Conservation 18:32953307.

Melson, S. L., M. E. Harmon, J. S. Fried, and J. B. Domingo, 2011. Estimates of live-tree carbon stores in the Pacific Northwest are sensitive to model selection. Carbon Balance and Management 6:2.

Milberg, P., J. Bergstedt, J. Fridman, G. Odell, and L. Westerburg. 2008. Observer bias and random variation in vegetation monitoring data. Journal of Vegetation Science 19:633-644.

Newman, C., C. D. Buesching, and D. Macdonald. 2003. Validating mammal monitoring methods and assessing the performance of volunteers in wildlife conservation- "Se quis custodiet ipsos custodies?" Biological Conservation 113:189197.

Phillips, D. L., S. L. Brown, P. E. Schroeder, and R. A. Birdsey. 2000. Toward error analysis of large-scale forest carbon budgets. Global Ecology and Biogeography 9:305-313.

Rodwell, J. S., editor. 1991. British plant communities. Volume 1: Woodlands and scrub. Cambridge University Press, Cambridge, UK.

RSPB (Royal Society for the Protection of Birds). 2011. www. rspb.org.uk

Savill, P. S., C. M. Perrins, K. J. Kirby, and N. Fisher. 2010. Wytham Woods: Oxford's ecological laboratory. Oxford University Press, Oxford, UK.

Schmeller, D. S., et al. 2008. Advantages of volunteer-based monitoring in Europe. Conservation Biology 23:307-316.

Shetty, P. 2011. Citizen scientists' climate-impact survey wraps up. Nature News. doi:10.1038/nature.2011.9697

Szabo, J. K., P. A. Vesk, P. W. J. Baxter, and H. P. Possingham. 2010. Regional avian species declines estimated from volunteer-collected long-term data using List Length Analysis. Ecological Applications 20:2157-2169.

Trumbull, D. J., R. Bonney, D. Bascom, and A. Cabral. 2000. Thinking scientifically during participation in a citizenscience project. Science Education 84:265-275.

Zianis, D., P. Muukkonen, R. Mäkipää, and M. Mencuccini. 2005. Biomass and stem volume equations for tree species in Europe. Silva Fennica 4:1-63. 